Results Mean age at presentation is 5.2 years (SD 1.8) [one month- 15 years]. During the sampled time frame (01/06/14-31/ $08 / 14$ ) there were a total of 54 presentations with a discharge diagnosis of conjunctivitis. $86 \%(25 / 29)$ were correctly diagnosed bacterial conjunctivitis. 52\% (13/25) were correctly diagnosed allergic conjunctivitis. 30 of the patients had documented features of bacterial conjunctivitis. 40\% (12/30) had an eye swabs taken. A total of 13 eye swabs were taken of which only one was indicated. $86 \%$ appropriately treated with topical antibiotics. $85 \%$ appropriately treated with antihistamines. $7 \%(3 / 41)$ were inappropriately treated with antihistamines. 28\% $(15 / 54)$ were referred for specialist opinion.

Discussion Conjunctivitis is a common presentation to a paediatrics emergency department. Indiscriminate use of microbiological investigations is a significant financial burden to the hospital and one, which can be easily eradicated. Prescribing of topical antibiotics or oral antihistamines should be based on sound clinical grounds so as to avoid unnecessary medicating of patients. Specialist referrals should be well considered.

\section{G104(P) RESUSCITATION EXPERIENCE OF PROFESSIONALS AT A DISTRICT GENERAL HOSPITAL (DGH)}

S Saeed, M Joishy. Paediatric Department, Ysbyty Gwynedd Hospital, Bangor, UK

\subsection{6/archdischild-2015-308599.103}

Introduction The caseload of critically ill patients at a DGH is usually smaller compared to tertiary hospitals. There are some concerns that modern centralisation of services may deskill clinicians at DGHs. Technology Enhanced Learning has an important role to play in improving training. We aimed to analyse professionals' experience, their role and confidence in performing resuscitation and also their opinion about simulation training.

Method We conducted a survey at Ysbyty Gwynedd to determine experience of medical and nursing colleagues in managing critically ill children and neonates over last 6 months. A questionnaire asking various aspects of resuscitation was sent out to nursing colleagues and paediatric doctors working at all levels. Of the 50 distributed questionnaires, 40 were completed and returned to us.

Results While only 30\% had exposure to resuscitation more than twice over preceding 6 months period, approximately $35 \%$ had once or no experience. Those who had exposure more than twice felt confident in performing resuscitation. While only $10 \%$ were involved in full cardiopulmonary resuscitation, about $30 \%$ were involved in airway and breathing and another 20\% in circulation. Over $90 \%$ stated that they would like to have regular simulation training at least monthly as they felt it will help in coping with actual resuscitation.

Conclusion There is limited data available in literature to determine frequency of managing critically ill children at individual level. This study shows that most health professionals have limited exposure to resuscitation situations at a DGH and nearly all paediatric staff wishes to receive regular simulation training.

\section{G105(P) YOUTH VIOLENCE: AN EDUCATIONAL SOLUTION?}

${ }^{1} \mathrm{CM}$ Reeder, ${ }^{2} \mathrm{CHN}$ Johnson. 'Medical School, University of Liverpool, Liverpool, UK; ${ }^{2}$ Medical School, University of Sheffield, Sheffield, UK

10.1136/archdischild-2015-308599.104
Background Violent/knife crime remains a significant public health challenge in the UK and Europe. Young people are disproportionately affected. Both physical injury in the short term and long term psychiatric conditions such as behavioural problems, post traumatic stress disorder, and substance misuse can result. ${ }^{1}$ Assault with a sharp instrument accounted for 3849 UK admissions to hospital last year $^{2}$ and so interventions which can reduce levels of violent crime and improve outcomes of victims of violent crimes are needed. StreetDoctors is a registered charity where basic life support and haemorrhage control sessions are taught to at risk young people in order to reduce mortality and morbidity from violent crimes. Since 2008 StreetDoctors has grown year on year to the point of expanding to 13 universities. Thanks to the hard work and dedication of the medical student volunteers we have taught well above 2500 young people ages 12-18.

Method A national approach was used to survey whether the young people were benefitting from our teaching. A pre and post teaching questionnaire was filled out by the young people to assess prior knowledge and knowledge gained

Results There was an Increase of $14.75 \%$ of young people knowing how to deal with someone who is passed out but breathing and an increase of $35.62 \%$ of young people knowing what to do when they found someone bleeding. A mean increase of 0.86 and of 0.92 points on a 1-10 scale answering the questions "how likely are you to help someone who's been stabbed/ is unconscious" respectively was also found.

Discussion This is the first time data has been collected across the country and our results show that the basic life support and haemorrhage control teaching we provide is having a positive impact on both the knowledge and willingness to help of the young people

\section{REFERENCES}

1 European report on preventing violence and knife crime among young people WHO, 2010

2 Recorded Offences Involving the Use of Weapons. Focus on Violent Crime and Sexual Offences, Chapter 3 2012/2013 Release. Office for National Statistics. Feb 2014.

\section{G106(P) INAPPROPRIATE AMBULANCE USE IN PAEDIATRICS}

K Blundell, E Abrahamson. Chelsea and Westminster Hospital, NHS, London, UK

\subsection{6/archdischild-2015-308599.105}

The use of the ambulance service and emergency department for non-urgent needs is considered a significant contributor to health system inefficiencies and a financial stressor. We performed a retrospective audit of children "inappropriately" transferred to a central London paediatric emergency department (PED) by ambulance during the period February to April of 2014. Inappropriate ambulance transfer was defined as children over the age of 2 years who did not require interventions or investigations in the PED, who had not been advised to call an ambulance by 111 or primary care services, and whose presenting complaints or diagnoses did not have any features which might be interpreted as worrying by non-medically trained caregivers. 512 patients were transferred to the PED by ambulance during the study period, of these $102(20 \%)$ were admitted to hospital. $309(60 \%)$ did not require any investigations or interventions (excluding observations and simple analgesia) and of these, 174 (33\%) were thought to represent potentially avoidable and "inappropriate" ambulance transfers. With finite resources and pressures on both the London ambulance service and PED 
services, research identifying reasoning behind caregiver choices, their understanding of healthcare options and the provision of further education and health information represent worthwhile steps in tackling this issue.

\section{G107(P) THE DEVELOPMENT OF A CONSULTANT PAEDIATRICIAN PHONE-LINE FOR GENERAL PRACTITIONERS}

RC Mitchell, 0 Akindolie. Department of Ambulatory Paediatrics, Kings College Hospital NHS Foundation Trust, London, UK

\subsection{6/archdischild-2015-308599.106}

Aims Ambulatory paediatric services have changed significantly over the last year at our hospital. One of these changes has been the development of a consultant-manned phone line, whereby general practitioners (GPs) can speak directly to a consultant paediatrician between 0800-2300 on weekdays and 0800-2000 at weekends. The aim was to optimise patient care by facilitating timely communication with the most appropriate hospital based paediatrician. This enables acutely unwell children and outpatient referrals to be directed appropriately, reducing paediatric emergency department (PED) attendances and it also serves to strengthen links between primary and secondary care.

Methods Activity data for the first five months was analysed. The consultants complete a proforma for each phone call with a predefined data set. This includes the general demographics of the caller and the patient in question, as well as information about the outcomes of calls.

Results 167 calls from GPs have been taken since the phone-line began and 59 of these have been recorded onto proformas. 29\% were from GPs asking for management advice and potential referral of outpatient problems, whereas 68\% were from GPs asking about the acute management of an unwell child in the GP surgery. There were a variety of different outcomes from the calls, directing the unwell child to the most appropriate practitioner (Figure 1). Consultants taking the phone calls recorded that $33 \mathrm{ED}$ attendances and 2 admissions had been prevented following calls from GPs.
Conclusion The phone-line has been very successful, reducing PED attendances and improving pathways of outpatient referrals. Not only does this service comply with 'Facing the Future' standards, as it is consultant delivered and available at times of peak activity, but it is also in accordance with the NHS Mandate, keeping children out of hospital, in the community wherever possible. The service is in its infancy, but thus far has been instrumental in the development of ambulatory paediatric services at our hospital. It provides excellent quality of care for local children and enhances our links with local GPs.

\section{G108(P) IN PAEDIATRIC CARDIOPULMONARY ARREST ARE SUPRAGLOTTIC AIRWAY DEVICES (SAD) ADEQUATE FOR OXYGENATING AND VENTILATING?}

E Day, N Sargant. Paediatric Emergency Department, Bristol Royal Children's Hospital, Bristol, UK

\subsection{6/archdischild-2015-308599.107}

Clinical scenario A two year old has a witnessed cardiopulmonary arrest whilst in your Emergency Department. You are able to ventilate the child using a bag valve mask (BVM) and oral pharyngeal airway, but notice his stomach is becoming inflated. In cardiac arrest in adults you know that a LMA or iGel is now the advised airway to use (ALS guidelines 2011), but you wonder if this could apply to children as well.

Search parameters MEDLINE (1950-present) and EMBASE (1980 to present) [(exp ventilation) AND (exp ped* OR paed* OR child) AND (exp arrest)] LIMIT: English.

Search outcomes 327 papers, 6 of which were relevant. A further two papers were found from the reference of one of the original search articles.

Comments No paper looks specifically at using a SAD in a paediatric arrest, all the cases have been in mannequins or in anaesthetised children, simulating arrest. Hypoxia, which is often the cause, is a very important factor to overcome in paediatric arrest. By using a SAD one can undertake uninterrupted chest compressions and ventilation. The comparison with BVM and intubation in the prehospital setting shows that neurological

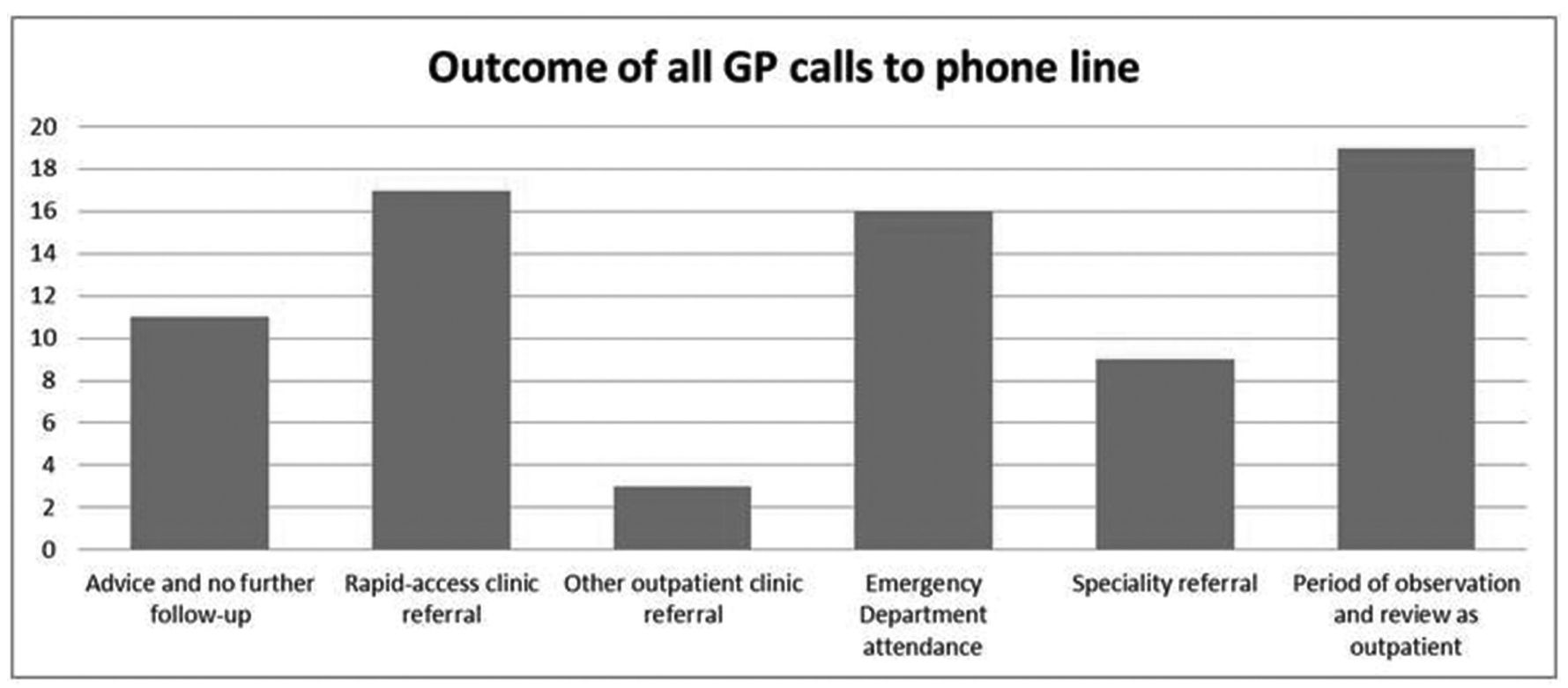

Abstract G107(P) Figure 1 The outcomes of all phone calls from GPs to the phone-line 